\title{
Cross-infectivity of oil palm by Phytophthora spp. isolated from perennial crops in
} Malaysia

\begin{abstract}
Bud rot disease or "Pudricion del cogollo" (PC) of oil palm is a major constraint on production in Colombia and neighbouring countries such as Brazil, Costa Rica, Ecuador, Nicaragua, Panama, Peru and Surinam. To date, there are no documented reports of Phytophthora disease of oil palm in South-East Asia. This research, therefore, was conducted to determine the pathogenic potential of Phytophthora palmivora and Phytophthora nicotianae on oil palm using both in vitro and nursery inoculation experiments. In vitro inoculation of both P. palmivora and P. nicotianae on immature oil palm leaflets caused discoloration within 2 days of inoculation and incubation at $25 \pm 1.5^{\circ} \mathrm{C}, 100 \% \mathrm{RH}$. Similarly, in nursery trials, lesions formed on the buds (unopened leaflets) 3 days after inoculation with P. palmivora or P. nicotianae zoospore suspensions. No lesions developed on untreated leaflets in either in vitro or nursery inoculation experiments. Phytophthora spp. were re-isolated from leaflet lesions and confirmed as the inoculated pathogens.
\end{abstract}

